Research

\title{
Plasmodium vivax dhfr and dhps mutations in isolates from Madagascar and therapeutic response to sulphadoxine-pyrimethamine
} Céline Barnadas*1, Magali Tichit ${ }^{4}$, Christiane Bouchier ${ }^{4}$, Arsène Ratsimbasoa ${ }^{2}$, Laurence Randrianasolo², Rogelin Raherinjafy ${ }^{3}$, Martial Jahevitra ${ }^{3}$, Stéphane Picot $^{1}$ and Didier Ménard ${ }^{3}$

Address: ${ }^{1}$ EA4170, Parasitology and Tropical Medicine, University Lyon 1, Lyon, France, ${ }^{2}$ Epidemiology Unit, Institut Pasteur de Madagascar, Antananarivo, Madagascar, ${ }^{3}$ Malaria Unit Research, Institut Pasteur de Madagascar, Antananarivo, Madagascar and ${ }^{4}$ Plate-forme Génomique, Institut Pasteur de Paris, Paris, France

Email: Céline Barnadas* - cbarnadas@free.fr; Magali Tichit - mtichit@pasteur.fr; Christiane Bouchier - bouchier@pasteur.fr; Arsène Ratsimbasoa - arsene@ pasteur.mg; Laurence Randrianasolo - laurence@ pasteur.mg; Rogelin Raherinjafy - raherinjafy@yahoo.fr; Martial Jahevitra - mjahevitra@yahoo.fr; Stéphane Picot - Stephane.Picot@sante.univ-lyon1.fr; Didier Ménard - dmenard@pasteur.mg

* Corresponding author

Published: 26 February 2008

Malaria Journal 2008, 7:35 doi:10.1186/1475-2875-7-35

This article is available from: http://www.malariajournal.com/content/7/I/35

(c) 2008 Barnadas et al; licensee BioMed Central Ltd.

This is an Open Access article distributed under the terms of the Creative Commons Attribution License (http://creativecommons.org/licenses/by/2.0), which permits unrestricted use, distribution, and reproduction in any medium, provided the original work is properly cited.
Received: 24 September 2007

Accepted: 26 February 2008

\begin{abstract}
Background: Four of five Plasmodium species infecting humans are present in Madagascar. Plasmodium vivax remains the second most prevalent species, but is understudied. No data is available on its susceptibility to sulphadoxine-pyrimethamine, the drug recommended for intermittent preventive treatment during pregnancy. In this study, the prevalence of $P$. vivax infection and the polymorphisms in the pvdhfr and pvdhps genes were investigated. The correlation between these polymorphisms and clinical and parasitological responses was also investigated in $P$. vivax-infected patients.
\end{abstract}

Methods: Plasmodium vivax clinical isolates were collected in eight sentinel sites from the four major epidemiological areas for malaria across Madagascar in 2006/2007. Pvdhfr and pvdhps genes were sequenced for polymorphism analysis. The therapeutic efficacy of SP in P. vivax infections was assessed in Tsiroanomandidy, in the foothill of the central highlands. An intention-to-treat analysis of treatment outcome was carried out.

Results: A total of I59 P. vivax samples were sequenced in the pvdhfr/pvdhps genes. Mutant-types in pvdhfr gene were found in $71 \%$ of samples, and in pvdhps gene in $16 \%$ of samples. Six non-synonymous mutations were identified in pvdhfr, including two novel mutations at codons 21 and I30. For pvdhps, beside the known mutation at codon 383, a new one was found at codon 422. For the two genes, different combinations were ranged from wild-type to quadruple mutant-type. Among the 16 patients enrolled in the sulphadoxine-pyrimethamine clinical trial (28 days of follow-up) and after adjustment by genotyping, 3 (I9\%, $95 \% \mathrm{Cl}: 5 \%-43 \%)$ of them were classified as treatment failure and were pvdhfr 58R/II7N double mutant carriers with or without the pvdhps 383G mutation.

Conclusion: This study highlights (i) that genotyping in the pvdhfr and pvdhps genes remains a useful tool to monitor the emergence and the spread of $P$. vivax sulphadoxine-pyrimethamine resistant in order to improve the national antimalarial drug policy, (ii) the issue of using sulphadoxine-pyrimethamine as a monotherapy for intermittent preventive treatment of pregnant women or children. 


\section{Background}

Plasmodium vivax remains the second most common cause of malaria in the world, infecting more than 80 million people annually. It is the most geographically widespread malaria parasite and it is found throughout South and Central America, Asia, the Middle East and parts of Africa [1].

Malaria is endemic throughout Madagascar, except in highland regions above $1,500 \mathrm{~m}$. Plasmodium falciparum is the dominant malaria species, but $P$. vivax and Plasmodium malariae have an increased prevalence in the foothills of the central highlands $[2,3]$. With over one million suspected cases reported in 2005, malaria remains one of the leading cause of morbidity and mortality in the country [4-6]. Although P. vivax causes less mortality than P. falciparum, it is responsible for significant morbidity and economic loss.

For the past 50 years, chloroquine was used as the first line treatment for malaria in Madagascar, with SP the second line treatment choice. In 2005, the National Malaria Control Programme (NMCP) decided to revise its treatment policy, replacing $\mathrm{CQ}$ by artemisinin-based combination therapy $(\mathrm{AQ}+\mathrm{AS}$, a combination of artesunate plus amodiaquine) and recommending SP for intermittent preventive treatment for pregnant women (IPTp) [7]. Some studies in vivo [8] and in vitro [9-11] have investigated the susceptibility of $P$. falciparum to this drug, but no data concerning the susceptibility of $P$. vivax to SP is available. Molecular and epidemiological studies have clearly shown that, as for P. falciparum, the major mechanism of resistance to SP involves specific point mutations in the $d h f r$ (dihydrofolate reductase) and $d h p s$ (dihydropteroate synthase) genes of the parasite. In total, 20 non-synonymous mutations have already been described in the $p v d h f r$ gene [12]. Some of these mutations (at codons 57, 58, 61, 117 and 173) are involved in resistance to pyrimethamine [12]. Five mutations have already been identified in the pvdhps gene, at codons 382, 383, 512, 553 and 585, corresponding to positions 436, 437, 540, 581 and 613 of the homologous gene in P. falciparum. No data is available about polymorphism in the pvdhfr and pvdhps genes of malaria parasites from Madagascar. Only one pvdhfr gene mutation, at codon 33, has been identified in some isolates (four of nine from Madagascar and the Comoro Islands), but this mutation has not been reported to be associated with clinical resistance or resistance in vitro $[13,14]$.

Since, it is difficult to monitor the susceptibility of $P$. vivax to antimalarial drugs by in vitro tests [15], molecular markers of drug resistance are useful tools for mapping the current and changing pattern of SP-resistant $P$. vivax isolates. The aims of this study were: (i) to assess polymor- phisms in the pvdhfr and pvdhps genes, using 159 P. vivax samples, and (ii) to correlate $p v d h f r / p v d h p s$ patterns with clinical and parasitological responses in $P$. vivax-infected patients.

\section{Methods}

Collection of clinical isolates of $\mathbf{P}$. vivax

Plasmodium vivax clinical isolates were collected in 2006/

2007 from individuals seeking treatment for malaria at government health facilities located in areas corresponding to the four epidemiological strata for malaria across Madagascar: Ejeda and Ihosy in the South (epidemicprone area), Tsiroanomandidy and Moramanga/Saharevo in the foothills of the Central Highlands (low-level endemic area), Maevatanana and Miandrivazo in the West (seasonal and endemic area) and Farafangana and Andapa in the East (periannual endemic area). All patients with fever or a history of fever in the $48 \mathrm{~h}$ before their arrival at the health centre were screened with the rapid diagnostic test (RDT), which is based on the detection of Plasmodium-specific lactate dehydrogenase (pLDH) (OptiMAL-IT ${ }^{\mathrm{Tm}}$, DiaMed $\mathrm{AG}^{\circ}$, Cressier sur Morat, Switzerland). Giemsa-stained thin and thick blood films were prepared for each patient with a positive RDT result. The various species of Plasmodium were identified and parasitaemia was assessed by a skilled microscopist. Once informed consent had been obtained from all adults and from at least one parent for minors, blood was collected on filter paper. Patients with positive microscopy results were promptly treated according to National Malaria Policy.

\section{SP efficacy}

The therapeutic efficacy of the sulphadoxine-pyrimethamine was assessed in P. vivax infections in 2006 in Tsiroanomandidy. The clinical protocol was reviewed and approved by the National Ethics Committee of the Ministry of Health and Family Planning of Madagascar $\left(\mathrm{N}^{\circ}\right.$ 102-SANPF-2006). Patients with blood smear confirmed $P$. vivax infection were enrolled based on the inclusion criteria given in WHO guidelines (2001) [16]. Informed consent was obtained from all adults and from at least one parent for minors and patients were treated with the standard SP regimen $(25 \mathrm{mg} / \mathrm{kg}$ sulphadoxine and 1.25 $\mathrm{mg} / \mathrm{kg}$ pyrimethamine as a single dose on day 0 ) and followed for 28 days. Each patient was weighed and medical history (including previous antimalarial medication) was recorded. Clinical examination, including axillary temperature recording, staining of serial thick and thin films, was performed on days $0,1,2,3,7,14$, and 28. Giemsastained thick and thin films were read by a skilled microscopist. Asexual- and sexual-stage parasites were counted, and counts expressed per 200 white blood cells. Parasitaemia was calculated on the basis of a white blood cell count of $8,000 / \mu \mathrm{l}$. Thick-film examinations were considered to 
be negative if no parasite was found in $100 \times$ high-power fields. Blood was blotted onto filter paper at various timepoints during follow-up and stored at $4{ }^{\circ} \mathrm{C}$ for DNA extraction. Haemoglobin concentration was measured on days 0 and 28 (HemoCue ${ }^{\circ}$, Anglholm, Sweden).

The primary end point was therapeutic response, based on parasitological and clinical cure by day 28, according to the $2001 \mathrm{WHO}$ protocol [16]. Therapeutic response was classified as "treatment failure" (TF; clinical deterioration due to $P$. vivax illness requiring hospitalization, with parasitaemia and axillary temperature $\geq 37.5^{\circ} \mathrm{C}$ any time between days 3 and 28, or parasitaemia on any day between days 7 and 28, regardless of clinical conditions) or "adequate clinical and parasitological response" (ACPR; absence of parasitaemia on day 28 without the criteria for TF previously being met). Patients with treatment failure were treated with artesunate $(4 \mathrm{mg} / \mathrm{kg}$ on days 0,1 , and 2) plus amodiaquine (10 mg/kg on days 0,1 , and 2$)$; however, their response to repeat therapy was not assessed.

Molecular genotyping techniques were used to distinguish recrudescences from reinfections for patients with treatment failure after day 7. Briefly, blood samples collected on the day of enrolment, on day 1 and on the day of treatment failure were analysed by sequencing for polymorphisms in the genes for circumsporozoïte protein (pvcsp) [17] and merozoite surface protein-3 (pvmsp3) $[18]$ and for six different microsatellite markers $[19,20]$ (Table 1). Microsatellite PCR products were size-genotyped by using a standard-size Genescan 500 LIZ on an ABI Prism 3730XL. The genotyping patterns on the day of failure were compared with those at treatment initiation and on day 1 . An outcome was defined as recrudescence if all alleles present at the time of failure were present at the time of treatment initiation or on day 1 , and defined as a reinfection otherwise.

The secondary end points were (i) fever clearance time, defined as the time (days) from initiation of treatment to the end of fever (i.e., patient remaining afebrile, based on reported history, with an axillary temperature of $<37.5^{\circ} \mathrm{C}$ on a given day of follow-up); (ii) parasite clearance time, defined as the time (days) from the initiation of treatment to parasite clearance (defined as the moment when parasite counts fell below the detection threshold for microscopy) and (iii) haematological recovery, defined as being cured on day 28 , with a haemoglobin level greater than that on day 0 .

\section{DNA extraction, pvdhfr/pvdhps amplication and sequencing}

DNA was extracted from blood spots with Instagene Matrix resin (BioRad ${ }^{\circ}$, Marnes la Coquette, France), according to the manufacturer's instructions. Parasite species were confirmed by real-time PCR, using species-specific primers previously described by de Monbrison [21], with a protocol adapted for the RotorGene ${ }^{\circledast} 3000$ thermocycler (Corbett Life Science ${ }^{\circledast}$, Sydney, Australia).

Plasmodium vivax isolates were genotyped for the pudhfr and $p v d h p s$ genes. DNA was amplified by semi-nested PCR for $p v d h f r$ gene amplification or by nested PCR for $p v d h p s$, using gene-specific primers $[22,23]$. PCR products were purified, using polyacrylamide P-100 Gel (Bio-Gel P-100, BioRad $^{\circledR}$, Marnes-la-Coquette, France), by 96-well plate filtration (Millipore ${ }^{\circledast}$, St. Quentin en Yvelines, France). Sequencing reactions were performed using ABI PRISM BigDye Terminator cycle sequencing ready reactions kit

Table I: Primer sequences of the microsatellite markers used for differentiating recrudescences from reinfections in paired samples from enrolled patients with treatment failure after day 7.

\begin{tabular}{|c|c|c|c|c|}
\hline Micro satellite markers & Motif & External PCR & Internal PCR & Label \\
\hline \multirow[t]{2}{*}{$14.185 \S$} & AT & F: TGCAGATATGCTGTCGAAT & F: GCAGTTGTTGCAGATTGAGC & 6FAM \\
\hline & & R: GGGAAAAACTTGGTCACAC & R: TAAGGCGTGCACGTTATCAT & \\
\hline \multirow[t]{2}{*}{$8.332 \S$} & AT & F: TGAAGCAATATAGCGATGAC & F: CCTCGATGGTGATGTGATGA & HEX \\
\hline & & R: CGGTGTAGTGTGGTACAATG & R: GTATAACATGGCACCCGACCT & \\
\hline \multirow[t]{2}{*}{$6.34 \S$} & $A C$ & F: CCCAATTAAGTGCAAATCA & F: TGAGCGCTTTAAGCTTCTGC & 6FAM \\
\hline & & R: CATGTAAAGAGGCACATGG & R: CAAAAATGAATCGTGGCACA & \\
\hline \multirow[t]{2}{*}{$2.21 \S$} & $A C$ & F: GGCAGGAACGTAGAGGAG & F: CCATCTGCTCAAATCCGAAG & 6FAM \\
\hline & & R: GGCTTGTTCATTTTTGAGGTA & R: GGCTCCTCCСTGTCTCTGTAG & \\
\hline \multirow[t]{2}{*}{ AY391734\# } & CA & F: TACCCCAGCCTTATCTCTC & F: TTTTCCCTTCGGAAAAACG & 6FAM \\
\hline & & R: AAATGCACAGACACTACGC & R: ACGACCATCACCTGCCATAG & \\
\hline \multirow[t]{2}{*}{ AY391740\# } & $A C$ & F: ATTTGTGTATGCCTTGTGTT & F: GTTTACCAGGCCCAATTCAC & HEX \\
\hline & & R: GTGAGGGTGTCTATCCGTA & R: GTTCACACGGGCGTATACAT & \\
\hline
\end{tabular}

\footnotetext{
$\S$ microsatellites sequences described by Imwong et al, 2006 [20]

\# microsatellites sequences described by Leclerc et al, 2004 [19]

Primers sequences were designed by primer3 software [39]

F: forward primer

R: reverse primer
} 
and run on a 3730 xl Genetic Analyzer (Applied Biosystems, Courtaboeuf, France). Electrophoregrams were visualized and analysed with $\mathrm{CEQ}^{\mathrm{TM}} 2000$ Genetic Analysis System software (Beckman Coulter ${ }^{\mathrm{rM}}$ ). Amino-acid sequences were compared with wild-type sequences (GenBank accession no. X98123 for pvdhfr and Genbank accession no. AY186730 for pvdhps), using BioEdit Sequence Alignment Editor software [24]. Parasites with mixed alleles (both wild-type and mutant alleles present) were considered to be mutant. A second PCR product was sequenced for confirmation if a new point mutation was observed.

\section{Nucleotide sequence accession number}

The complete sequences of the alleles identified has been submitted to GenBank and assigned accession numbers EU168419 to EU168431 for pvdhfr and EU176992 to EU177003 for pvdhps.

\section{Statistical analysis}

Data were input into EpiInfo $6.04^{\circ}$ software (Centers for Disease Control and Prevention, Atlanta, Georgia, United States), checked and analysed, using MedCalc ${ }^{\odot}$ software version 9.1.0.1 (MedCalc Software, Broekstraat 52, 9030 Mariakerke, Belgium) and Comprehensive meta-analysis software version 2 (Biostat, Englewood, NJ 07631, USA).

An intention-to-treat analysis of treatment outcome was carried out. Frequencies were compared using chi-squared tests, and continuous variables were compared using Student's t-tests or Mann-Whitney U-tests, as appropriate. All reported p-values are for two-tailed tests and were considered statistically significant if less than 0.05 .

\section{Results}

\section{Prevalence of $\mathbf{P}$. vivax infections}

From January to October 2006 and March to July 2007, 8,363 patients were screened by using RDT. Among these patients, the global prevalence of $P$. vivax infections was estimated at $6.3 \%$ (135 cases) of all malaria infections by microscopy. Considerable heterogeneity was observed between the different study areas and prevalence ranged from zero in Andapa to $17.5 \%$ in Tsiroanomandidy (Figure 1).

\section{Analysis of the pvdhfr and pvdhps genes}

159 P. vivax samples, corresponding to the 135 cases completed with 24 collected in the same conditions, were sequenced on $p v d h f r / p v d h p s$ genes (Figure 1). A large proportion of these samples $(71 \%, 113 / 159)$ had at least one mutation on the pvdhfr gene; this proportion ranged from $18 \%$ in Ejeda (2/11) to $100 \%$ in Ihosy and Farafangana $(1 / 1)$. These samples displayed non-synonymous mutations at six residues, including four mutations known to be responsible for pyrimethamine resistance (P33L,
C49R, S58R and S117N) and two previously unknown mutations (P21S and $\mathrm{N} 130 \mathrm{~K})$. The most prevalent mutant-type alleles were S58R (58\%) and S117N $(63.5 \%)$, particularly for study sites on the western side of Madagascar. The mutant P33L allele, which has been reported to be specific to Madagascar, was found in only $6 \%$ of isolates and was not restricted to any particular area. The fourth mutation, C49R, was present in 3\% of the isolates and was limited to Maevatanana. The two new non-synonymous mutations, P21S and N130K, were identified in two and 50 isolates, respectively, at only two sites (Miandrivazo and Tsiroanomandidy). An additional synonymous mutation was detected at amino-acid 15 (gca $\rightarrow$ gcg) in 69 samples (43\%). No variation in the number of repeats was observed in the polymorphic region between nucleotides 262 and 309 [25].

Non-synonymous mutations were found at two residues of the pvdhps gene, in 25 of the 159 isolates: 24 samples (15\%) displayed the A383G mutant allele and one sample $(0.6 \%)$ the C422R mutant allele. No mutant alleles were found at southern sites and such alleles were surprisingly rare in Miandrivazo (3\%), despite $83 \%$ of the isolates from this site having mutant alleles of the pvdhfr gene. Based on the pvdhps tandem repeat region located between amino-acid residues 603 to 658 of the reference sequence, nine different genotypes, including the reference genotype, were identified. All the A383G mutanttype isolates were from the same genotype. These changes and the corresponding positions of mutations in pvdhfr and pvdhps are shown in Table 2.

In total, 15 different genotypes were identified, as presented in Table 3, including wild-type and single, double or triple mutant-types in for $p v d h f r$ and the wild-type or single mutants for pvdhps. Only $27.7 \%$ of the 159 isolates sequenced were wild-type for both genes, and all but two of the parasites with mutant genotypes for pvdhps (98.7\%) also had mutant genotypes for pvdhfr. Four single mutant allele genotypes were observed for pvdhfr, but none of these genotypes was ever associated with mutation in the pvdhps gene. In the double-mutant genotype, the $130 \mathrm{~K}$ mutation was combined with $33 \mathrm{~L}$ or $117 \mathrm{~N}$ mutations in the pvdhfr gene, in the absence of mutation in the pvdhps gene. The pvdhfr $58 \mathrm{R} / 117 \mathrm{~N}$ double mutant accounted for $25.8 \%$ of isolates, $10.1 \%$ of which also had the A383G mutation in the pvdhps gene. Finally, two triple-mutant pvdhfr genotypes were observed, with and without mutations in the pvdhps gene. The $49 \mathrm{R} / 58 \mathrm{R} / 117 \mathrm{~N}$ genotype was found only in Maevatanana, whereas the $58 \mathrm{R} / 117 \mathrm{~N} / 130 \mathrm{~K}$ genotype was found mostly in Miandrivazo and Tsiroanomandidy. 
Equatorial stratum Tropical stratum Highlands South stratum

Maevatanana $22(8.2 \%)$

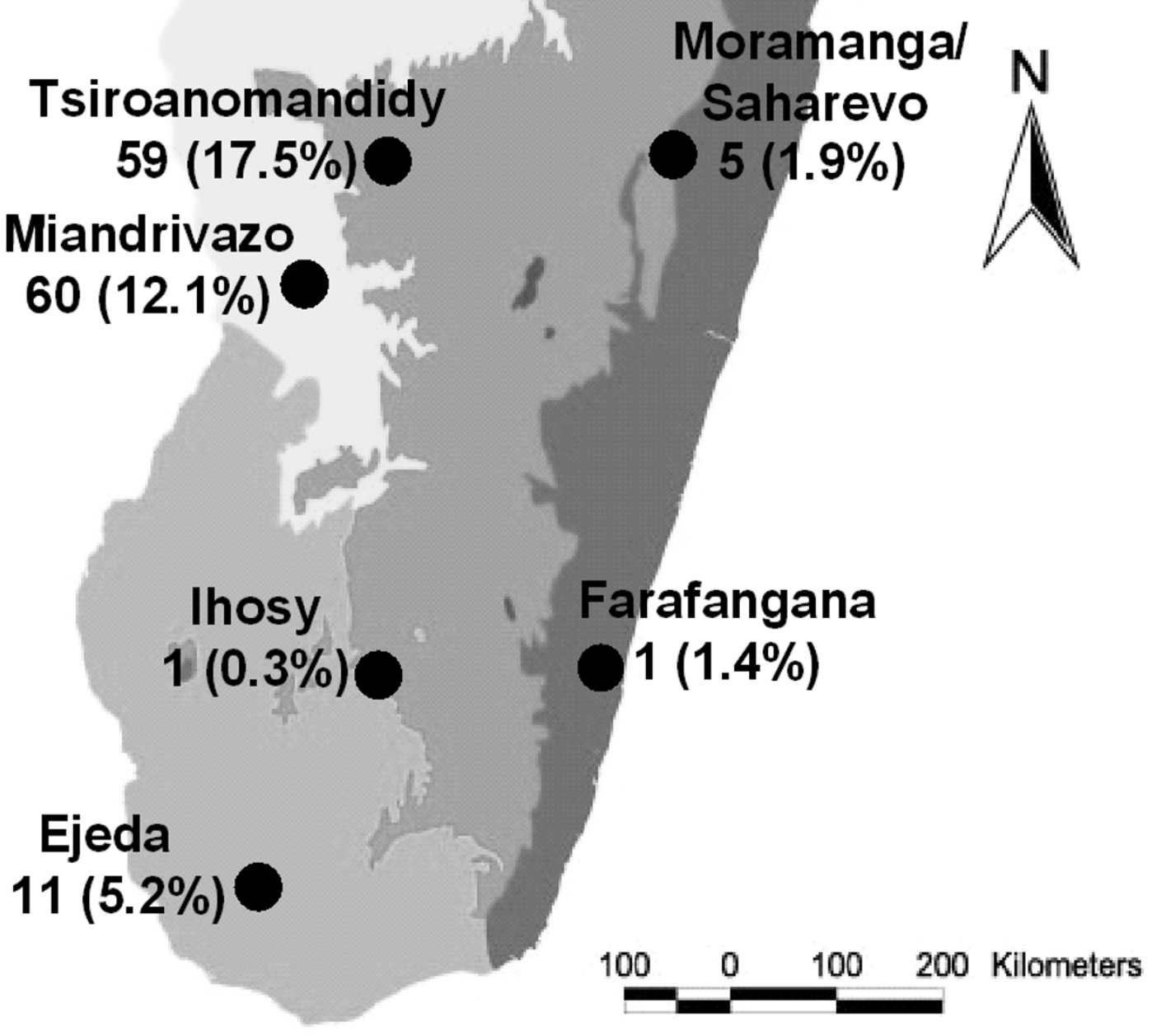

Figure I Map of Madagascar showing the distribution of $P$. vivax isolates from each study area. 
Table 2: Frequency distribution of mutant-type alleles for DHFR and DHPS domains in I59 Malagasy isolates collected from 7 sites in 2006-2007

\begin{tabular}{|c|c|c|c|c|c|c|c|c|c|c|c|c|}
\hline \multirow{3}{*}{ Sampling sit } & & \multirow{3}{*}{$\begin{array}{l}\text { No. of } \\
\text { isolates }\end{array}$} & \multicolumn{7}{|c|}{ P. vivax dhfr polymorphism } & \multicolumn{3}{|c|}{ P. vivax dhps polymorphism } \\
\hline & & & \multirow{2}{*}{$\begin{array}{c}\text { No. of } \\
\text { mutant } \\
\text { isolates } \\
(\%)\end{array}$} & \multicolumn{6}{|c|}{ Amino-acid residue } & \multirow{2}{*}{$\begin{array}{c}\text { No. of } \\
\text { mutant } \\
\text { isolates } \\
(\%)\end{array}$} & \multicolumn{2}{|c|}{ Amino-acid residue } \\
\hline & & & & P2IS & P33L & C49R & S58R & SIITN & NI30K & & A383G & C422R \\
\hline \multirow[t]{2}{*}{ South } & Ejeda & II & $2(18)$ & - & 1 & - & I & 1 & - & $0(0)$ & 0 & 0 \\
\hline & Ihosy & 1 & $\mathrm{I}(100)$ & - & - & - & - & 1 & - & $0(0)$ & 0 & 0 \\
\hline \multirow[t]{2}{*}{ West } & $\begin{array}{l}\text { Miandriva } \\
\text { zo }\end{array}$ & 60 & $50(83)$ & I & I & - & 43 & 47 & 44 & $2(3)$ & I & 1 \\
\hline & $\begin{array}{l}\text { Maevatana } \\
\text { na }\end{array}$ & 22 & $14(64)$ & - & 2 & 5 & 12 & 12 & - & $8(36)$ & 8 & 0 \\
\hline \multirow{2}{*}{$\begin{array}{l}\text { Central } \\
\text { Highlands }\end{array}$} & Tdd & 59 & $42(7 I)$ & 1 & 4 & - & 33 & 37 & 6 & II (19) & 11 & 0 \\
\hline & $\begin{array}{l}\text { Moraman } \\
\text { ga }\end{array}$ & 5 & $3(60)$ & - & 1 & - & 2 & 2 & - & $3(60)$ & 3 & 0 \\
\hline East & $\begin{array}{l}\text { Farafangan } \\
\text { a }\end{array}$ & 1 & I (100) & - & - & - & 1 & I & - & I (100) & 1 & 0 \\
\hline Total & & 159 & $113(7 \mid)$ & $2(1.3)$ & $9(5.7)$ & $5(3.1)$ & $92(57.9)$ & $101(63.5)$ & $50(31.4)$ & $25(16)$ & $24(15)$ & I (0.6) \\
\hline
\end{tabular}

Residues displaying new mutations are indicated in bold typeface

Tdd: Tsiroanomandidy

Clinical and parasitological response to SP

to day 28 for 15 of the 16 patients enrolled in the clinical Clinical and parasitological monitoring was complete up study of SP efficacy. Nine of these 16 patients were male

Table 3: Frequency distribution of pvdhfr/pvdhps genotypes in 159 Malagasy isolates collected from 7 sites in 2006-2007

\begin{tabular}{|c|c|c|c|c|c|c|c|c|c|}
\hline \multirow{3}{*}{ dhfr alleles } & \multirow{3}{*}{ dhps alleles } & \multicolumn{7}{|c|}{ Sampling sites } & \multirow{3}{*}{$\begin{array}{l}\text { Total isolates } \\
\text { (frequency \%) }\end{array}$} \\
\hline & & \multicolumn{2}{|c|}{ South } & \multicolumn{2}{|c|}{ West } & \multicolumn{2}{|c|}{ Central Highlands } & \multirow{2}{*}{$\begin{array}{c}\text { East } \\
\text { Farafangana }\end{array}$} & \\
\hline & & Ejeda & Ihosy & Maevatanana & Miandrivazo & Tdd & Moramanga & & \\
\hline \multicolumn{10}{|l|}{ No mutation } \\
\hline \multirow[t]{2}{*}{ Wild-type } & Wild-type & 9 & - & 7 & 10 & 17 & 1 & - & $44(27.7)$ \\
\hline & $383 G$ & - & - & I & - & - & I & - & $2(1.3)$ \\
\hline \multicolumn{10}{|l|}{ Single mutant } \\
\hline 215 & Wild-type & - & - & - & I & I & - & - & $2(1.3)$ \\
\hline $33 \mathrm{~L}$ & Wild-type & I & - & 2 & - & 4 & I & - & $8(5.0)$ \\
\hline $117 \mathrm{~N}$ & Wild-type & - & 1 & - & 3 & 3 & - & - & $7(4.4)$ \\
\hline I30K & Wild-type & - & - & - & I & - & - & - & I (0.6) \\
\hline \multicolumn{10}{|l|}{ Double mutant } \\
\hline $33 \mathrm{~L}+130 \mathrm{~K}$ & Wild-type & - & - & - & 1 & - & - & - & $\mathrm{I}(0.6)$ \\
\hline $117 N+130 K$ & Wild-type & - & - & - & I & I & - & - & $2(1.3)$ \\
\hline \multirow[t]{2}{*}{$58 R+117 N$} & Wild-type & I & - & 4 & 2 & 18 & - & - & $25(15.7)$ \\
\hline & $383 G$ & - & - & 3 & - & 10 & 2 & 1 & $16(10.1)$ \\
\hline \multicolumn{10}{|l|}{ Triple mutant } \\
\hline \multirow[t]{3}{*}{$49 R+58 R+117 N$} & Wild-type & - & - & 1 & - & - & - & - & $\mathrm{I}(0.6)$ \\
\hline & $383 G$ & - & - & 4 & - & - & - & - & $4(2.5)$ \\
\hline & Wild-type & - & - & - & 39 & 4 & - & - & $43(27.0)$ \\
\hline \multirow{2}{*}{$58 R+117 N+130 K$} & $422 \mathrm{R}$ & - & - & - & 1 & - & - & - & I (0.6) \\
\hline & $383 G$ & - & - & - & I & 1 & - & - & $2(1.3)$ \\
\hline
\end{tabular}


and seven were female (43.4\%). They were aged from nine months to 42 years (median 7.5 years), and had a median weight of $16.5 \mathrm{~kg}$ (range 7.5 to 52.5). Fifteen patients $(93.8 \%)$ had suffered fever during the 48 hours immediately preceding enrolment and one declared having taken antimalarial drugs (tetracycline). Neither microscopy nor real-time PCR showed mixed infections $(P$. vivax with other species). The geometric mean of asexual parasite count was 3,353 parasites/ $\mu \mathrm{L}$ (range 500 to $21,500)$ at baseline. None of the patients had detectable gametocytes on microscopy at day 0 or during follow-up. Mean haemoglobin concentration was $7.5 \mathrm{~g} / \mathrm{dL}$ on day 0 , and the mean increase in haemoglobin concentration observed on day 28 was $1.3 \mathrm{~g} / \mathrm{dL}$. Eleven patients successfully cleared $P$. vivax parasitaemia after SP treatment, whereas four patients presented a reoccurrence of parasitaemia on days 14,21 or 28 . The final classification of the recrudescent patients after adjustment by genotyping is shown in Table 4 . The treatment failure rate at day 28 by intention-to-treat analysis was also estimated to $25 \%$ (95\% CI: 8-50) and after adjustment by genotyping to $19 \%$ (95\% CI: 5-43). Mean fever clearance time was calculated as $1.2 \pm 0.7$ days and, parasite clearance time was calculated as $1.3 \pm 0.9$ days.

\section{pvdhfr/pvdhps genotypes and clinical response to SP}

No significant differences were observed between recrudescent and non-recrudescent patients in terms of sex ratio, mean temperature at day 0 , mean age, initial mean parasitaemia, haemoglobin concentration and mean number of mutations in pvdhfr/pvdhps genes (Table 5).
The $p v d h f r / p v d h p s$ genotype and therapeutic response of each isolate evaluated are listed in Table 6 . Three of the four patients carrying the pvdhfr/pvdhps triple-mutant genotype (58R/117N, 383G) displayed ACPRs. The remaining patient was classified treatment failure at day 28 . Considering the pvdhfr double mutant $58 \mathrm{R} / 117 \mathrm{~N}$ genotype, all 3 patients displaying treatment failure and 6 over the 11 displaying ACPRs carried it, providing an odd ratio for TF of 8.27 with a wide $95 \%$ CI of 0.35-197.6. The molecular/therapeutic outcome relationship can't be clearly depicted from these data.

\section{Discussion}

This study highlights the real burden of $P$. vivax infections by updating prevalence data in eight sites throughout Madagascar. Despite the likely underestimation of the prevalence of $P$. vivax due to the use of the RDT for malaria screening [2], this study confirms, however, that $P$. vivax is the second prevalent species in malaria infections after $P$. falciparum. The highest prevalence of Plasmodium vivax infections were found in the western side of Madagascar, certainly because of the predominance of ethnic groups of Indo-Asian and Middle Eastern origin, who carry the Duffy antigen [26].

SP resistance and related single nucleotide polymorphisms (SNPs) in the pvdhfr and pvdhps genes were analysed in $P$. vivax samples from seven sites representative of the four major epidemiological strata for malaria. The two genes were screened by sequencing, to identify possible new mutations. The P. vivax pudhfr gene is known to be

Table 4: Paired analysis of pvcsp, pvmsp3 and microsatellite markers sequences used for differentiating recrudescences from reinfections for the four patients with a reoccurrence of parasitemia (Tsiroanomandidy, Madagascar, 2006).

\begin{tabular}{|c|c|c|c|c|c|c|c|c|c|c|}
\hline \multirow[b]{2}{*}{ Patient } & \multirow[b]{2}{*}{ Day } & \multicolumn{6}{|c|}{ Allele sizes of microsatellites markers (bp) } & \multicolumn{2}{|c|}{ Genotypes in } & \multirow[b]{2}{*}{ Final classification } \\
\hline & & 6.34 & L34 & 2.21 & 8.332 & 14.185 & L40 & pvcsp gene & pvmsp3 gene & \\
\hline \multirow[t]{3}{*}{ TDD062079 } & 0 & $221 / 225$ & 108 & 196 & 217 & $89 / 91$ & 97 & VK210 & A & Recrudescence \\
\hline & I & $221 / 225$ & 108 & 196 & 217 & 91 & 97 & VK210 & $A$ & \\
\hline & 14 & 225 & 108 & 196 & 217 & 91 & 97 & VK210 & $A$ & \\
\hline \multirow[t]{3}{*}{ TDD06viv 12} & 0 & 219 & $108 / 110$ & 196 & 222 & na & 97 & VK210 & na & Recrudescence \\
\hline & I & 219 & $108 / 110$ & 196 & 222 & na & 97 & VK210 & na & \\
\hline & 28 & 219 & 110 & 196 & 222 & na & 97 & VK210 & na & \\
\hline \multirow[t]{3}{*}{ TDD06viv15 } & 0 & 225 & 110 & 196 & na & 98 & 97 & VK210 & na & Reinfection or Relapse \\
\hline & 1 & 230 & 104 & 205 & na & 93 & 97 & VK210 & na & \\
\hline & 21 & 225 & 108 & 196 & na & 91 & 97 & VK210 & na & \\
\hline \multirow[t]{3}{*}{ TDD06viv20 } & 0 & 230 & 108 & 198 & na & 91 & 97 & VK210 & $A$ & Recrudescence \\
\hline & I & 230 & 108 & 198 & na & 91 & 97 & VK210 & $A$ & \\
\hline & 14 & 230 & 108 & 198 & na & 91 & 97 & VK210 & A & \\
\hline
\end{tabular}

na: not available

Two infections (TDD062079 and TDD06viv12) were polyclonal as indicated by microsatellite markers analysis.

pvcsp sequences were classified as VK210 or VK247 types as described [17]; after DNA sequences alignment, no SNP was observed between day 0 , $\mathrm{I}$ and the day of reoccurent parasitemia.

pvmsp3 sequences were classified into types A (1900 bp), B (1300 bp) or C (I I00 bp) as described [40]; after DNA sequences alignment, one SNP was observed between TDD062079 at day 0 and the sequences obtained from both days I and I4. No differences were observed between TDD06viv20 sequences. 
Table 5: Demographic, clinical and parasitological characteristics of baseline isolates from recrudescent and non-recrudescent patients (Tsiroanomandidy, Madagascar, 2006).

\begin{tabular}{|c|c|c|c|c|c|c|c|}
\hline & \multicolumn{6}{|c|}{ Patients } & \multirow{3}{*}{$P$} \\
\hline & \multicolumn{3}{|c|}{ Recrudescent } & \multicolumn{3}{|c|}{ Non-Recrudescent } & \\
\hline & No & Value & $\mathrm{Cl} 95 \%$ & No & Value & $\mathrm{Cl} 95 \%$ & \\
\hline \multicolumn{8}{|l|}{ Patient charasteristics } \\
\hline No of males/No of females & 3 & $3 / 0$ & - & 11 & $4 / 7$ & - & \\
\hline Age (years), mean & 3 & 5.3 & $0-15.6$ & II & 14.7 & $5.3-24.0$ & NS \\
\hline Temperature $\left({ }^{\circ} \mathrm{C}\right)$, mean & 3 & 38.8 & $35.8-41.9$ & II & 38.0 & $37.6-38.4$ & NS \\
\hline \multicolumn{8}{|l|}{ Hematology } \\
\hline Hemoglobin concentration $(\mathrm{g} / \mathrm{dL})$, mean & 3 & 6.8 & $5.5-8.1$ & 11 & 7,5 & $5.1-9.9$ & NS \\
\hline \multicolumn{8}{|l|}{ Isolates at the baseline } \\
\hline Parasitemia (parasites $/ \mu \mathrm{L}$ ), geometric mean & 3 & 3434 & $361-32627$ & II & 3307 & $1603-6823$ & NS \\
\hline Mean number of mutations in $d h f r / d h p s$ genes & 3 & 2.3 & $1.6-3$ & II & $\mathrm{I} .4$ & $0.6-2.2$ & NS \\
\hline
\end{tabular}

One patient presenting a $P$. falciparum infection and the one presenting a $P$. vivax reinfection (or relapse, as indicated by genotyping analysis) were excluded from the non-recrudescent patients group.

highly diverse, supporting the use of such an approach [27]. A very high proportion of mutant-type isolates $(72.2 \%)$ and diverse alleles were identified in these isolates, with 15 different mutant-type alleles observed if both pvdhfr and pvdhps gene mutations were taken into account. This is the first time that mutations at positions implicated in SP resistance have been described in P. vivax isolates from Madagascar.

Only two substitutions were identified in pvdhps, whereas six non-synonymous mutations, including four that have already been described, were found in pvdhfr. Mutations in these two genes do not play identical roles in the emergence of SP-resistance. Similar observations have been made for $P$. falciparum $[28,29]$. Mutations seem occurring first in $p f d h f r$ gene, then after in $p f d h p s$ gene when most of the parasites in the population have double- or triplemutant alleles of the dhfr gene [22].

Mutations in pvdhfr, including $58 \mathrm{R}$ and $117 \mathrm{~N}$, have been implicated in pyrimethamine resistance. The 58R allele was found in $58 \%$ of all $P$. vivax isolates, in combination with $117 \mathrm{~N}$, which was found alone or in combination with other mutations in $63.5 \%$ of all isolates. Studies in vitro have shown that the mutation of a single base, leading to the replacement of a serine by an asparagine residue at codon 117 , increases the $\mathrm{IC}_{50}$ value of pyrimethamine by more than 80 times. The combination of this mutation

Table 6: The pvdhfr/pvdhps genotypes and therapeutic responses of 15 patients from Tsiroanomandidy (Madagascar, 2006) treated with sulphadoxine-pyrimethamine for $P$. vivax infections

\begin{tabular}{|c|c|c|c|c|c|c|c|}
\hline \multicolumn{8}{|c|}{ Sequence polymorphism in } \\
\hline \multicolumn{2}{|c|}{ Patient } & \multicolumn{3}{|c|}{ pvdhfr } & \multirow{2}{*}{$\begin{array}{c}\text { Pvdhps } \\
383\end{array}$} & \multirow[t]{2}{*}{ No. of mutations in the 2 genes } & \multirow[t]{2}{*}{ Therapeutic response ${ }^{b}$} \\
\hline Trial no. & Age (Years) & 33 & 58 & 117 & & & \\
\hline VIV7 & 2 & $P$ & S & $S$ & $A$ & 0 & ACPR \\
\hline 60446 & 2.5 & $P$ & S & S & $A$ & 0 & ACPR \\
\hline VIVI4 & 7 & $\mathbf{L}$ & S & S & A & 1 & ACPR \\
\hline VIVI8 & 13 & $\bar{P}$ & $\mathrm{~S}$ & $S$ & A & 0 & ACPR \\
\hline 60756 & 42 & $P$ & $S$ & S & $A$ & 0 & ACPR \\
\hline VIV3 & 12 & $P$ & $\mathbf{R}$ & $\mathbf{N}$ & G & 3 & ACPR \\
\hline VIV8 & 34 & $\mathrm{P}$ & $\mathrm{S}$ & $\mathbf{N}$ & $A$ & I & ACPR \\
\hline VIV20 & 9 & $P$ & $\mathbf{R}$ & $\mathbf{N}$ & $A$ & 2 & $\mathrm{TF}$ \\
\hline 62298 & 5 & $P$ & $\mathbf{R}$ & $\mathbf{N}$ & A & 2 & ACPR \\
\hline 60250 & 6 & $P$ & $\mathbf{R}$ & $\mathbf{N}$ & $A$ & 2 & ACPR \\
\hline 60149 & 8 & $P$ & $\mathbf{R}$ & $\mathbf{N}$ & G & 3 & ACPR \\
\hline VIV4 & 30 & $P$ & $\mathbf{R}$ & $\mathbf{N}$ & G & 3 & ACPR \\
\hline VIVI2 & 6 & $\mathrm{P}$ & $\mathbf{R}$ & $\mathbf{N}$ & G & 3 & TF \\
\hline 62079 & 0.8 & $P$ & $\mathbf{R}$ & $\mathbf{N}$ & A & 2 & TF \\
\hline VIVI5 & 2 & $P$ & $\mathbf{R}$ & $\mathbf{N}$ & A & 2 & Reinfection or relapse \\
\hline
\end{tabular}


with the replacement of a serine by an arginine residue at codon 58 generates an enzyme more than 400 times more resistant to pyrimethamine than the wild-type enzyme $[30,31]$. The $57 \mathrm{~L} / 58 \mathrm{R} / 117 \mathrm{~N}$, triple mutant previously observed in Thailand [14] and associated with low levels of parasite clearance was not found. No parasites of the 57L/58R/61M/117T quadruple mutant type, associated with a high risk of SP treatment failure, were also not found.

Two new mutations were found at codons 21 and 130 in the pvdhfr gene. The mutation at codon 130 accounted for $31.4 \%$ of the isolates. This mutation, present mostly at Miandrivazo (67\% of isolates), was strongly associated with the 58R/117N double mutant. The P33L substitution accounted for only $6 \%$ of the isolates. This mutation was previously found to be associated with isolates of Comorian or Malagasy origin [14,25]. One of the unique features of the pvdhfr gene of $P$. vivax is the presence of a tandem repeat between amino-acid residues 70 and 110 . Size polymorphism has been reported in this region $[22,32]$, but no variation was observed in this study.

It was impossible to assess the impact of the new N130K mutation based on clinical data, because only the 58R/ $117 \mathrm{~N}$ double mutant was observed in isolates from the patients enrolled in the clinical trial of SP efficacy, including the isolate with the A383G mutation in pvdhps. The use of yeast constructs might facilitate interpretation of the role of this mutation in resistance [33].

Because of the absence of a genotyping consensus protocol for $P$. vivax to differentiate recrudescence from reinfection, the use of a combination of different genes such as pvama1, pumsp1, pumsp3 or microsatellite markers in paired analysis seems to be the safest available method. In this study, $p v c s p$ and $p v m s p 3$ genes sequencing and six different microsatellite markers were used on samples from day 0 , day 1 and day of reoccurrence. The use of microsatellite markers seems to be useful as more polyclonal infections could be detected. Obvioulsy, the main limitation of this protocol was the well-recognized impossibility to prove that a $P$. vivax reoccurrence was a recrudescence, a relapse or a reinfection.

No significant association between pvdhfr/pvdhps polymorphisms and SP-treatment outcome was found, but all recrudescent patients were pvdhfr double-mutant carrier. This result strongly suggests that infection due to the $p v d$ $h f r 58 \mathrm{R} / 117 \mathrm{~N}$ double mutant is necessary but not sufficient for SP treatment failure to occur. The treatment outcome is likely to be favourable if the parasite has a wild-type genotype, but in parasites with mutations, outcome depends on the alleles present at the pvdhfr and pvdhps loci and the individual response of the patient [12].
Currently, it is well known that beside parasite factors, host factors such as nutritional status, immune response and rates of drug metabolism are involved in determining treatment outcome.

Surprisingly, almost $72.3 \%$ of the tested $P$. vivax isolates had mutations in the pvdhfr and/or pvdhps genes, despite SP never having been recommended as a first-line treatment for malaria, but only as a second-line treatment from 1998 to 2005. ACT is now recommended for the treatment of uncomplicated malaria regardless of the causal Plasmodium species. Nevertheless, self-treatment remains frequent in Madagascar since unpublished study has shown that three quarters of all febrile patients attending government health facilities have already used chloroquine in $67.6 \%$ of cases, cotrimoxazole (sulphamethoxazol/trimethoprim) in $23.4 \%$ and SP in $9.4 \%$ of cases. Cotrimoxazole is the drug most widely used to treat diarrhoea as well as respiratory infections [34]. Asymptomatic P. vivax infections and treatment with trimethoprim are probably common, resulting in the exposure of parasites to this drug. Mutations in the pvdhfr and $p v d h p s$ genes may reflect overall antifolate drug pressure in Madagascar.

Previous studies have shown that $d h f r$ mutant $P$. falciparum isolates were extremely rare [35], with only one case of infection with the $108 \mathrm{~N}$ mutant reported in the south of Madagascar. Based the observations for P. vivax isolates, data for $P$. falciparum genotypes should be updated.

\section{Conclusion}

SP has been recommended for intermittent preventive treatment during pregnancy since 2005 in Madagascar. The regional office of the WHO for Africa currently recommends IPTp with SP in countries with a parasitological failure rate of less than 50\% [36]. With a frequency of TF estimated at $19 \%$ and a prevalence of up to $17.5 \%$ of all malaria cases, $P$. vivax infections remains a public health problem in Madagascar and there is no doubt that SP will not be completely effective in IPTp strategy $[37,38]$. The extensive use of SP will increase the drug selection pressure on the parasite and favour the spread of resistance. As a result, this study highlights (i) that genotyping in the pvdhfr gene remains a useful tool to monitor the emergence and the spread of $P$. vivax SP-resistant in order to improve the national antimalarial drug policy, (ii) the issue of using SP as a monotherapy for IPT of pregnant women or children.

\section{Authors' contributions}

$\mathrm{CBa}$ performed laboratory work and wrote the manuscript. MT and CBo carried out sequencing and gave constructive advice. AR, LR and RR performed the field work. 
MJ performed laboratory work. SP helped with the writing of the manuscript and gave constructive advice. DM was involved in all stages of this study.

\section{Acknowledgements}

We thank the patients and healthcare workers involved in the national network for the surveillance of malaria resistance in Madagascar (Réseau d'Etude de la Résistance, RER) from which these samples were obtained, and the staff of the Ministry of Health of Madagascar for their collaboration. We thank Hanitra Ranaivosoa, Didier Ralaizandry, Daimondra Raveloariseheno and Vony Rabekotorina for helping with field work.

This work was supported by grant from the French Ministry of Foreign Affairs, FSP/RAI 200I-168 project. Sample collection was funded by the Global Fund project for Madagascar round 3 (Community Action to Roll Back Malaria, Grant number: MDG-304-G05-M).

$\mathrm{CBa}$ is a $\mathrm{PhD}$ student supported by the Fondation Jeunesse Internationale (Fondation de France), BioMérieux "Prix BioMérieux infectiologie 2006", Association des Internes et Anciens Internes en Pharmacie des Hôpitaux de Lyon "Prix R. Rizard", and the Hospices Civils de Lyon.

\section{References}

I. Mendis K, Sina BJ, Marchesini P, Carter R: The neglected burden of Plasmodium vivax malaria. Am J Trop Med Hyg 200 I, 64(I-2 Suppl):97-I06.

2. Ratsimbasoa A, Randriamanantena A, Raherinjafy R, Rasoarilalao N, Menard D: Which malaria rapid test for Madagascar? Field and laboratory evaluation of three tests and expert microscopy of samples from suspected malaria patients in Madagascar. Am J Trop Med Hyg 2007, 76(3):48I-485.

3. Robert V, Le Goff G, Andrianaivolambo L, Randimby FM, Domarle O, Randrianarivelojosia M, Raharimanga $\mathrm{V}$, Raveloson A, Ravaonjanahary C, Ariey F: Moderate transmission but high prevalence of malaria in Madagascar. Int J Parasitol 2006, 36( (12): I 273-I28I.

4. Enquête auprès des Ménages. Institut National de la Statistique de Madagascar; 2002:71-83.

5. Jeremiah M SA: Mortalité des enfants de moins de $\mathbf{5}$ ans à Madagascar. Enquête Démographique et de la Santé III à Madagascar 2004:I9I-20I.

6. UNICEF: Multiple Indicator Cluster Survey (MICS). 2000.

7. Rabarijaona LP RT Ranaivo LH, Raharimalala LA, Rakotomanana F, Rakotondraibe EM, Ramarosandratana B, Rakotoson JD, Rakotonjanabelo LA, Tafangy PB: Paludisme sur les hautes terres centrales de Madagascar: stratégies de lutte. Méd Trop 2006, 66(5):504-5I2.

8. Randrianasolo L, Randriamanantena A, Ranarivelo L, Ratsimbasoa A, Domarle O, Randrianarivelojosia M: Monitoring susceptibility to sulfadoxine-pyrimethamine among cases of uncomplicated, Plasmodium falciparum malaria in Saharevo, Madagascar. Ann Trop Med Parasitol 2004, 98(6):55 I-554.

9. Randrianarivelojosia M, Ariey F, Raharimalala LA, Parzy D, Rogier C, Jambou R: Current absence of pyrimethamine resistance of Plasmodium falciparum in Madagascar. Trans $R$ Soc Trop Med Hyg 2002, 96(5):557-559.

10. Randrianarivelojosia M, Harisoa JL, Rabarijaona LP, Raharimalala LA, Ranaivo L, Pietra V, Duchemin JB, Rakotomanana F, Robert V, Mauclere $\mathrm{P}$, Ariey $\mathrm{F}$ : In vitro sensitivity of Plasmodium falciparum to amodiaquine compared with other major antimalarials in Madagascar. Parassitologia 2002, 44(3-4): $14 \mid-147$.

II. Rason MA, Ariey F, Rafidimanantsoa L, Andrianantenaina BH, Sahondra Harisoa JL, Randrianarivelojosia M: Monitoring the drug-sensitivity of Plasmodium falciparum in coastal towns in Madagascar by use of in vitro chemosensitivity and mutation detection tests. Parasite 2002, 9(3):247-253.

12. Hawkins VN, Joshi H, Rungsihirunrat K, Na-Bangchang K, Sibley $\mathrm{CH}$ : Antifolates can have a role in the treatment of Plasmodium vivax. Trends Parasitol 2007, 23(5):213-222.

13. de Pecoulas PE, Tahar R, Ouatas T, Mazabraud A, Basco LK: Sequence variations in the Plasmodium vivax dihydrofolate reductase-thymidylate synthase gene and their relationship with pyrimethamine resistance. Mol Biochem Parasitol 1998, 92(2):265-273.

14. Imwong M, Pukrittakayamee S, Looareesuwan S, Pasvol G, Poirreiz J, White NJ, Snounou G: Association of genetic mutations in Plasmodium vivax dhfr with resistance to sulfadoxine-pyrimethamine: geographical and clinical correlates. Antimicrob Agents Chemother 200I, 45(II):3I22-3I 27.

15. Udomsangpetch R, Kaneko O, Chotivanich K, Sattabongkot J: Cultivation of Plasmodium vivax. Trends Parasitol 2008, 24(2):85-88.

16. WHO: Monitoring antimalarial drug resistance, Report of a WHO consultation. Geneva, Switzerland, World Health Organization; 2002.

17. Imwong M, Pukrittayakamee S, Gruner AC, Renia L, Letourneur F, Looareesuwan S, White NJ, Snounou G: Practical PCR genotyping protocols for Plasmodium vivax using Pvcs and Pvmspl. Malar J 2005, 4(I):20.

18. Bruce MC, Galinski MR, Barnwell JW, Snounou G, Day KP: Polymorphism at the merozoite surface protein-3alpha locus of Plasmodium vivax: global and local diversity. Am J Trop Med Hyg 1999, 6 I (4):5। 8-525.

19. Leclerc MC, Durand P, Gauthier C, Patot S, Billotte N, Menegon M, Severini C, Ayala FJ, Renaud F: Meager genetic variability of the human malaria agent Plasmodium vivax. Proc Natl Acad Sci U S A 2004, I0I(40): I 4455-14460.

20. Imwong M, Sudimack D, Pukrittayakamee S, Osorio L, Carlton JM, Day NP, White NJ, Anderson TJ: Microsatellite variation, repeat array length, and population history of Plasmodium vivax. Mol Biol Evol 2006, 23(5):1016-1018.

21. de Monbrison F, Angei C, Staal A, Kaiser K, Picot S: Simultaneous identification of the four human Plasmodium species and quantification of Plasmodium DNA load in human blood by real-time polymerase chain reaction. Trans $R$ Soc Trop Med Hyg 2003, 97(4):387-390

22. Imwong M, Pukrittayakamee S, Renia L, Letourneur F, Charlieu JP, Leartsakulpanich U, Looareesuwan S, White NJ, Snounou G: Novel point mutations in the dihydrofolate reductase gene of Plasmodium vivax: evidence for sequential selection by drug pressure. Antimicrob Agents Chemother 2003, 47(5): I5I4-I52I.

23. Korsinczky M, Fischer K, Chen N, Baker J, Rieckmann K, Cheng Q: Sulfadoxine resistance in Plasmodium vivax is associated with a specific amino acid in dihydropteroate synthase at the putative sulfadoxine-binding site. Antimicrob Agents Chemother 2004, 48(6):2214-2222.

24. Hall TA: BioEdit: a user-friendly biological sequence alignment editor and analysis program for Windows 95/98/NT. Nucl Acids Symp Ser 1999:95-98.

25. Eldin de Pecoulas P, Basco LK, Tahar R, Ouatas T, Mazabraud A Analysis of the Plasmodium vivax dihydrofolate reductasethymidylate synthase gene sequence. Gene 1998, 2II(I): 177-I85.

26. Hurles ME, Sykes BC, Jobling MA, Forster P: The dual origin of the Malagasy in Island Southeast Asia and East Africa: evidence from maternal and paternal lineages. Am J Hum Genet 2005, 76(5):894-90I.

27. Hastings MD, Maguire JD, Bangs MJ, Zimmerman PA, Reeder JC, Baird $\mathrm{JK}$, Sibley $\mathrm{CH}$ : Novel Plasmodium vivax dhfr alleles from the Indonesian Archipelago and Papua New Guinea: association with pyrimethamine resistance determined by a Saccharomyces cerevisiae expression system. Antimicrob Agents Chemother 2005, 49(2):733-740.

28. Nzila AM, Mberu EK, Sulo J, Dayo H, Winstanley PA, Sibley CH, Watkins WM: Towards an understanding of the mechanism of pyrimethamine-sulfadoxine resistance in Plasmodium falciparum: genotyping of dihydrofolate reductase and dihydropteroate synthase of Kenyan parasites. Antimicrob Agents Chemother 2000, 44(4):991-996.

29. Nzila AM, Nduati E, Mberu EK, Hopkins Sibley C, Monks SA, Winstanley PA, Watkins WM: Molecular evidence of greater selective pressure for drug resistance exerted by the long-acting antifolate Pyrimethamine/Sulfadoxine compared with the shorter-acting chlorproguanil/dapsone on Kenyan Plasmodium falciparum. J Infect Dis 2000, I 8 I (6):2023-2028.

30. Hastings MD, Porter KM, Maguire JD, Susanti I, Kania W, Bangs MJ, Sibley CH, Baird JK: Dihydrofolate reductase mutations in Plasmodium vivax from Indonesia and therapeutic response to 
sulfadoxine plus pyrimethamine. J Infect Dis 2004, 189(4):744-750.

31. Hastings MD, Sibley CH: Pyrimethamine and WR99210 exert opposing selection on dihydrofolate reductase from Plasmodium vivax. Proc Natl Acad Sci U S A 2002, 99(20): |3|37-13 |4|.

32. Kaur S, Prajapati SK, Kalyanaraman K, Mohmmed A, Joshi H, Chauhan VS: Plasmodium vivax dihydrofolate reductase point mutations from the Indian subcontinent. Acta Trop 2006, 97(2): $174-180$.

33. Djapa LY, Basco LK, Zelikson R, Rosowsky A, Djaman JA, Yonkeu JN, Bolotin-Fukuhara M, Mazabraud A: Antifolate screening using yeast expressing Plasmodium vivax dihydrofolate reductase and in vitro drug susceptibility assay for Plasmodium falciparum. Mol Biochem Parasitol 2007, I 56(I):89-92.

34. Randrianarivelojosia M RL Randriamanantena A, Jambou R: Chimiorésistance de Plasmodium falciparum sur les régions cotières malgaches. Méd Trop 2000, 60:243-249.

35. Randrianarivelojosia M RL Parzi D, Roux JF, Jambou R: DHFR and Plasmodium falciparum resistance to antifolates: search for other mutations in the Indian Ocean region. Bull Soc Path Exot 1999, 92:282.

36. WHO: WHO Expert Comittee on Malaria. Geneva, Switzerland, World Health Organization; 2000.

37. Nosten F, McGready R, Simpson JA, Thwai KL, Balkan S, Cho T, Hkirijaroen L, Looareesuwan S, White NJ: Effects of Plasmodium vivax malaria in pregnancy. Lancet 1999, 354(9 I 78):546-549.

38. Singh N, Shukla MM, Sharma VP: Epidemiology of malaria in pregnancy in central India. Bull World Health Organ 1999, 77(7):567-572.

39. Rozen S, Skaletsky H: Primer3 on the WWW for general users and for biologist programmers. Methods Mol Biol 2000, 132:365-386.

40. Rayner JC, Corredor V, Feldman D, Ingravallo P, Iderabdullah F, Galinski MR, Barnwell JW: Extensive polymorphism in the Plasmodium vivax merozoite surface coat protein MSP-3alpha is limited to specific domains. Parasitology 2002, I 25(Pt 5):393-405.

Publish with Bio Med Central and every scientist can read your work free of charge

"BioMed Central will be the most significant development for disseminating the results of biomedical research in our lifetime. "

Sir Paul Nurse, Cancer Research UK

Your research papers will be:

- available free of charge to the entire biomedical community

- peer reviewed and published immediately upon acceptance

- cited in PubMed and archived on PubMed Central

- yours - you keep the copyright

Submit your manuscript here:

http://www.biomedcentral.com/info/publishing_adv.asp
BioMedcentral 